\title{
Factors Affecting Successful Equity Crowdfunding
}

\author{
Ying Li, Hongduo Cao*, Tengjuan Zhao \\ Business School, Sun Yat-sen University, Guangzhou, China \\ Email: mnsliy@mail.sysu.edu.cn, *caohd@mail.sysu.edu.cn
}

How to cite this paper: Li, Y., Cao, H.D. and Zhao, T.J. (2018) Factors Affecting Successful Equity Crowdfunding. Journal of Mathematical Finance, 8, 446-456. https://doi.org/10.4236/jmf.2018.82028

Received: April 17, 2018

Accepted: May 26, 2018

Published: May 29, 2018

Copyright $\odot 2018$ by authors and Scientific Research Publishing Inc. This work is licensed under the Creative Commons Attribution International License (CC BY 4.0).

http://creativecommons.org/licenses/by/4.0/

\begin{abstract}
This study examines the factors that influence successful equity crowdfunding, using data from the website www.dajiatou.com to develop models based on investors' willingness to invest, financing efficiency, and the herding effect, which are all related to the successful financing of projects. The results show that financing objectives, assignment of shares, and the number of inquiries have a significant impact on investors' willingness to invest; the minimum initial investment amount and the number of inquiries have a significant impact on financing efficiency, and early investment affects the decision-making behavior of investors later in the process via the herding effect.
\end{abstract}

\section{Keywords}

Equity Crowdfunding, Successful Financing, Influencing Factors, Herding Effect

\section{Introduction}

In the context of the entrepreneurial boom and financing difficulties faced by entrepreneurs, the crowdfunding model has emerged as a new form of financing. Using the Internet, crowdfunding helps project sponsors to release projects to and obtain finance from a wide range of people regardless of spatial distances.

Following recent developments in science and technology and social media, crowdfunding has emerged as an innovative financing method for SMEs. Crowdfunding allows entrepreneurs to initiate projects through the Internet and seek public support without the involvement of financial intermediaries, thereby reducing the cost of finance [1]. This overcomes problems related to space and time, and connects entrepreneurs with investors. The emergence of crowdfunding has partially solved the financing problems that enterprises face when they 
commence, grow, and innovate [2] [3], and thus it has become an important way to solve financing problems faced by SMEs. For project sponsors and crowdfunding platforms, the question "what aspects of the project can improve the chances of success of crowdfunding?" is worthy of attention. Therefore, this study examines the factors influencing successful equity crowdfunding, using data from the Chinese website www.dajiatou.com to analyze investors' willingness to invest, financing efficiency, and the existence of the herding effect. The results have practical implications for the initiation of crowdfunding projects.

\section{Research Status}

The concept of crowdfunding was first proposed by Sullivan (2006), and later defined as group cooperation whereby "people pool funds through the Internet to support projects that are initiated by others or organizations" [4]. Participants include project sponsors, investors, and crowdfunding platforms [5]. There are four types of crowdfunding based on the nature of returns to investors: equity, credit, public welfare, and reward [6].

Equity crowdfunding involves project sponsors releasing projects through the Internet under a company structure, with investors able to obtain returns on their shares in the company. Credit crowdfunding, also known as peer-to-peer (P2P) online lending, involves individual borrowers applying for personal microfinance through the Internet, without the need for financial intermediaries and mortgages, with investors obtaining rewards via a predetermined rate of return. Public welfare crowdfunding relates to non-profit crowdfunding. The purpose of public welfare crowdfunding is to support public welfare or creative projects, and supporters of these projects do not require any financial return. Reward crowdfunding generally encourages investors to invest in physical products or services via pre-sales of those goods or services.

Domestic and foreign scholars have studied various factors that affect the success of crowdfunding. First, the rigor of the crowdfunding website in terms of the selection and review of projects and whether areas are established for communication between project sponsors and supporters both have an impact on the success of crowdfunding [7] [8]. Different crowdfunding models also affect the probability of success. De Buysere et al. (2012) believe that the probability of success is greater when either the equity crowdfunding or revenue-sharing crowdfunding model is used [9]. Entrepreneurs' academic qualifications, patent levels, whether they have experience as executives, whether they have previously initiated projects, and their individual social networks are the key factors affecting the success of crowdfunding [1] [10]. The influence of investors on successful financing of crowdfunding is mainly reflected in the geographical location and the number of supporters at initial crowdfunding.

Second, the characteristics and quality of the project itself are important factors in successful crowdfunding. Project characteristics, such as the industry to which the project belongs, the nature of the project, and project release data, as 
well as factors related to the project financing plan, such as financial objectives, the duration of financing, the minimum initial investment required, shares to be transferred in equity crowdfunding, and the level of rewards are all important [11]. In addition, project information posted by the project sponsor on the crowdfunding website, such as product ideas, videos, pictures, and business plans, are important indicators of project quality. Timely updates by sponsors can serve to increase investor confidence. The type of project also has an impact on crowdfunding. Mollick (2014) found that design and technology projects are the most popular types of projects on crowdfunding websites and that these types of projects enjoy a higher success rate [1].

A review of previous studies on crowdfunding shows that crowdfunding has received extensive attention from scholars as an emerging method of financing new projects. However, there is a lack of depth in the existing literature. Overall, there have been numerous studies on reward crowdfunding, while most of the studies on equity crowdfunding have focused on supervision and relevant laws and policies. Therefore, this study uses data from the Chinese website www.dajiatou.com to conduct an empirical analysis of the factors influencing the success of equity crowdfunding projects.

\section{Models}

\subsection{Data Source}

This study uses data on successful equity crowdfunding projects from the website www.dajiatou.com. Since its establishment in October 2012, the website has listed a total of 70 projects that were successful in obtaining financing. After projects with partially incomplete data were excluded, data from 64 projects were available for analysis. The types of information that were obtained are shown in Table 1.

\subsection{Establishment of Models}

\subsubsection{Investment Willingness Model}

On the website www.dajiatou.com, investors can choose their intentional

Table 1. Equity crowdfunding project information.

\begin{tabular}{ll}
\hline Information category & Contents included \\
\hline Basic project information & Project industry, city, team size, and stage \\
Financing time & Project releasing time, financing completion time, and financing duration \\
Funding amount & $\begin{array}{l}\text { Minimum starting investment amount, financing objectives, actual financing, intentional amount, } \\
\text { financing completeness, and number of assigning shares }\end{array}$ \\
Project sponsor information & $\begin{array}{l}\text { Academic background, whether he/she has entrepreneurial experience, has been an executive, and has } \\
\text { initiated other projects }\end{array}$ \\
Platform Information & $\begin{array}{l}\text { Number of browsing, number of collectors, number of successful investors, number of inquirers, and } \\
\text { number of project evaluations }\end{array}$ \\
Lead investor information & Leading investment amount, and ratio of lead investor's investment
\end{tabular}


investment before they make real investment, and then enter the stage of payment. Therefore, the amount of intentional investment can be used to indicate the investment willingness in the project and the investment willingness of investors who have the willingness to invest. Therefore, this study uses investors' willingness to invest as the dependent variable $Y=$ (Intention amount) $/($ goal amount). Based on the literature review and the specific conditions outlined on the website, we selected nine factors affecting investors' willingness to invest as independent variables.

The independent variables in relation to a project's basic attributes include project stage, team size, and number of evaluations of the project. The website www.dajiatou.com identifies five project stages: non-initiated, product developing, product launched or marketed, profit earned, and profitable. In this study, these stages are signified by a value between 0 and 5 , with a larger value indicating a more mature project stage. Team size reflects the strength of the project to a certain extent, whereby a larger project team enables stronger project execution and implementation. The number of evaluations refers to the number of comments that are posted in the project commentary area. This serves as an index of the level of interest and activity from supporters of the project. The relevant factors when setting up a project financing plan include financing objectives, share assignment, and the minimum initial investment amount. The financing objectives are the project sponsor's estimate of the funds that are required for project development. Share assignment refers to the investors' return on investment from equity crowdfunding. The minimum initial investment amount represents the investment threshold for investors wanting to invest in an equity crowdfunding project. The numbers of people browsing, collectors, and inquiries on the website www.dajiatou.com indicate the attractiveness of the project to investors at various stages.

This study proposes and tests the following hypotheses.

Hypothesis 1a: a more mature project stage means a greater willingness to invest by investors.

Hypothesis 1b: a larger team size means a greater willingness to invest by investors.

Hypothesis 1c: a greater number of evaluations means a greater willingness to invest by investors.

Hypothesis 2a: a higher level of financing objectives means a lower willingness to invest by investors.

Hypothesis $2 \mathrm{~b}$ : more shares assigned by the project party means a lower willingness to invest by investors.

Hypothesis 2c: a higher minimum initial investment amount means a lower willingness to invest by investors.

Hypothesis 3a: a greater number of people browsing means a greater willingness to invest by investors.

Hypothesis $3 \mathrm{~b}$ : a greater number of collectors means a greater willingness to invest by investors. 
Hypothesis 3c: a greater number of inquiries means a greater willingness to invest by investors.

This study also develops and applies the following regression model:

$$
\begin{aligned}
Y= & \alpha_{0}+\alpha_{1} X_{1}+\alpha_{2} X_{2}+\alpha_{3} X_{3}+\alpha_{4} X_{4}+\alpha_{5} X_{5} \\
& +\alpha_{6} X_{6}+\alpha_{7} X_{7}+\alpha_{8} X_{8}+\alpha_{9} X_{9}+\varepsilon
\end{aligned}
$$

where $Y$ is the investors' willingness to invest; $X_{1}$ is the level of financing objectives; $X_{2}$ is the number of shares assigned; $X_{3}$ is the minimum initial investment amount; $X_{4}$ is the project stage; $X_{5}$ is the team size; $X_{6}$ is the number of evaluations; $X_{7}$ is the number of people browsing; $X_{8}$ is the number of collectors; $X_{9}$ is the number of inquiries; and $\varepsilon$ is the random error.

\subsubsection{Financing Efficiency Model}

In crowdfunding, the financing efficiency of the project is of concern to the project sponsor. If the financing can be achieved with greater efficiency, the implementation of the project will be accelerated and the time cost of project will be reduced. In this study, financing efficiency is the dependent variable $\mathrm{W}$ and the amount of money that is financed in unit time represents the level of financing efficiency. Then, $W=$ (real amount $) /$ time. Nine factors relating to the basic project attributes, financing plan settings, and crowdfunding platform are selected as the independent variables.

This study proposes and tests the following hypotheses.

Hypothesis 4a: a more mature project stage means greater financing efficiency.

Hypothesis 4b: a larger team size means greater financing efficiency.

Hypothesis 4c: a greater number of evaluations means greater financing efficiency.

Hypothesis 5a: a greater number of financing objectives means lower financing efficiency.

Hypothesis 5b: more shares assigned by the project party means lower financing efficiency.

Hypothesis $5 \mathrm{c}$ : a higher minimum initial investment amount means lower financing efficiency.

Hypothesis 6a: a greater number of people browsing means greater financing efficiency.

Hypothesis 6b: a greater number of collectors means greater financing efficiency.

Hypothesis 6c: a greater number of inquiries means greater financing efficiency.

This paper also develops the following regression model:

$$
\begin{aligned}
W= & \beta_{0}+\beta_{1} X_{1}+\beta_{2} X_{2}+\beta_{3} X_{3}+\beta_{4} X_{4}+\beta_{5} X_{5} \\
& +\beta_{6} X_{6}+\beta_{7} X_{7}+\beta_{8} X_{8}+\beta_{9} X_{9}+\varepsilon
\end{aligned}
$$

where $W$ is financing efficiency; $X_{1}$ is the level of financing objectives; $X_{2}$ is the number of shares assigned; $X_{3}$ is the minimum initial investment amount; $X_{4}$ is 
the project stage; $X_{5}$ is the team size; $X_{6}$ is the number of evaluations; $X_{7}$ is the number of people browsing; $X_{8}$ is the number of collectors; $X_{9}$ is the number of inquiries; and $\varepsilon$ is the random error.

\subsubsection{Herding Effect Model}

The herding effect is widely studied in fields such as financial investment. The generation of the herding effect requires two conditions to be met: 1) there is information asymmetry, and the vulnerable party must be unable to obtain more information about the strong party; 2) other people's behavior can be observed. In the crowdfunding process, these two conditions are met. To examine the herding effect, this study sets the dependent variable as the market share (S) of financing and measures the change in $\mathrm{S}$ on the $\mathrm{t}^{\text {th }}$ day of financing. Independent variables are divided into two areas: project party's information and predecessor's investment behavior. The project party's information includes the basic attributes of the project (project stage, team size, and number of evaluations) and the financing plan settings (financing objectives, number of shares assigned, and minimum initial investment amount). The predecessor's investment behavior mainly takes the progress of project financing as the factor, and uses the percentage of the total financing that has been received on the $\mathrm{t}^{\text {th }}$ day of the project as the index.

This study proposes and tests the following hypothesis.

Hypothesis 7: in the crowdfunding process, the percentage of funds that is received early in the project influences the investment decisions of later investors via the herding effect.

To examine the herding effect, this study uses the MNL market share model, which is represented as follows:

$$
\begin{aligned}
\ln \left(\frac{S_{i t}}{\tilde{S}_{t}}\right)= & \alpha_{i}+\gamma_{1}\left(X_{1}-\overline{X_{1}}\right)+\gamma_{2}\left(X_{2}-\overline{X_{2}}\right)+\gamma_{3}\left(X_{3}-\overline{X_{3}}\right) \\
& +\gamma_{4}\left(X_{4}-\overline{X_{4}}\right)+\gamma_{5}\left(X_{5}-\overline{X_{5}}\right)+\gamma_{6}\left(X_{6 t}-\overline{X_{6 t}}\right) \\
& +\gamma_{7}\left(X_{7 t}-\overline{X_{7 t}}\right)+\varepsilon_{i}, \text { where, } S_{i t}=\frac{A_{i t}}{\sum_{i=1}^{I} A_{i t}}
\end{aligned}
$$

where $A_{i t}$ is the difference between the amount of project $i$ that has been financed on day $t_{2}$ and that on day $t_{1}\left(t_{2}>t_{1}\right) ; S_{i t}$ is the market share that is increased for project $i$ on day $t_{2} ; X_{1}$ is the number of financing objectives; $X_{2}$ is the number of shares assigned; $X_{3}$ is the minimum initial investment amount; $X_{4}$ is the project stage; $X_{5}$ is the team size; $X_{6}$ is the number of evaluations; $X_{7}$ is the percentage of the required funding that is financed; $\bar{S}_{t}$ is the geometric mean of $S_{i t} ; \overline{X_{k t}}$ is the arithmetic mean of $X_{i k e}$; and $\varepsilon_{i}$ is the error value.

\section{Results and Discussion}

\subsection{Willingness to Invest Model}

From the results in Table 2, we can see that the regression model can be 
Table 2. Regression results for the willingness to invest model.

\begin{tabular}{|c|c|c|c|c|c|c|c|}
\hline \multirow{2}{*}{ Model } & \multicolumn{2}{|c|}{ Non-Std. Coeff. } & \multirow{2}{*}{$\begin{array}{c}\text { Std. Coeff. } \\
\text { Trial Version }\end{array}$} & \multirow{2}{*}{$\mathrm{t}$} & \multirow{2}{*}{ Sig. } & \multicolumn{2}{|c|}{ Co-linear Statistics } \\
\hline & B & Std. Err. & & & & Tolerance & VIF \\
\hline (Constant) & 1.808 & 0.428 & & 4.229 & 0.000 & & \\
\hline Financing objectives & -0.016 & 0.002 & -0.631 & -2.120 & 0.039 & 0.134 & 7.475 \\
\hline Assigning shares & -1.600 & 0.619 & -0.255 & -2.643 & 0.011 & 0.657 & 1.523 \\
\hline $\begin{array}{l}\text { Minimum starting } \\
\text { investment amount }\end{array}$ & -0.088 & 0.101 & -0.228 & -0.874 & 0.186 & 0.174 & 5.731 \\
\hline stage of project & 0.081 & 0.101 & 0.098 & 0.805 & 0.424 & 0.806 & 1.241 \\
\hline Team size & 0.011 & 0.009 & 0.074 & 0.454 & 0.499 & 0.449 & 2.226 \\
\hline Number of evaluations & 0.001 & 0.006 & -0.017 & -0.129 & 0.898 & 0.677 & 1.478 \\
\hline Number of browsing & 0.009 & 0.000 & 0.070 & 0.547 & 0.487 & 0.714 & 1.401 \\
\hline Number of collectors & -0.004 & 0.006 & -0.079 & -0.559 & 0.579 & 0.587 & 1.703 \\
\hline Number of inquirers & 0.025 & 0.005 & 0.409 & 3.106 & 0.003 & 0.683 & 1.465 \\
\hline
\end{tabular}

a. Dependent variable: investors' investment willingness

expressed as:

$$
\begin{aligned}
Y= & 1.808-0.016 X_{1}-1.6 X_{2}-0.088 X_{3}+0.081 X_{4}+0.011 X_{5} \\
& +0.001 X_{6}+0.009 X_{7}-0.004 X_{8}+0.025 X_{9}
\end{aligned}
$$

It can be seen that at the $5 \%$ significance level, three factors, namely, financing objectives, number of shares assigned, and number of inquiries, have a significant impact on investors' willingness to invest. However, the other factors do not have a significant impact.

The three factors included in the basic attributes of a project have a positive impact on investors' willingness to invest. A more mature project stage means greater willingness to invest by investors, indicating that projects in the profitable stage are more popular and favored by investors. This result supports Hypothesis 1a. A larger team size means a greater willingness to invest by investors, which supports Hypothesis 1b. A greater number of evaluations means more support for the project from investors, which supports Hypothesis 1c.

Number of shares assigned has the most significant impact on investors' willingness to invest, and shows a negative correlation. The more shares that are assigned, the lower the investors' willingness to invest, which supports Hypothesis $2 \mathrm{a}[10]$. There is a significant negative correlation between the level of financing objectives and investors' willingness to invest, indicating that the greater the financing objectives, the lower the investors' willingness to invest, which supports Hypothesis 2b [1] [10]. There is a negative correlation between the minimum initial investment amount and investors' willingness to invest. A lower minimum initial investment amount can reduce the investor's investment threshold and enable them to spread their investment risk, which supports Hypothesis $2 \mathrm{c}$.

Both the number of people browsing and the number of inquiries show a pos- 
itive correlation with investors' willingness to invest, which supports Hypotheses $3 \mathrm{a}$ and $3 \mathrm{c}$. However, the number of collectors shows a negative correlation with investors' willingness to invest, which does not support Hypothesis $3 \mathrm{~b}$. We found that for most projects, the number of collectors was less than the number of inquiries, indicating that investors who make inquiries may not necessarily collect the project, so the number of collectors may not be used to explain investors' investment willingness well.

\subsection{Financing Efficiency Model}

From Table 3, it can be seen that at the $10 \%$ significance level, the minimum initial investment amount and the number of inquiries have a significant impact on financing efficiency. However, the other factors do not have a significant impact.

The minimum initial investment amount is negatively correlated with financing efficiency, which means that a lower minimum initial investment amount leads to more efficient financing of a project, which supports Hypothesis 5c. There is a negative relationship between the number of shares assigned and financing efficiency, which supports Hypothesis 5b. The level of financing objectives shows a positive correlation with financing efficiency, which does not support Hypothesis 5a. We found that financing occurs earlier for projects with greater financing objectives. There is more preparation and promotion of such projects, making it possible to quickly attract attention and investment when the project is launched, while investors who make early investments provide further publicity by word of mouth, thereby demonstrating the herding effect, which is confirmed via empirical analysis in the third model.

The basic attributes of a project, namely, project stage, team size, and number

Table 3. Regression results for the financing efficiency model.

\begin{tabular}{|c|c|c|c|c|c|c|c|}
\hline \multirow{2}{*}{ Model } & \multicolumn{2}{|c|}{ Non-Std. Coeff. } & \multirow{2}{*}{$\begin{array}{c}\text { Std. Coeff. } \\
\text { Trial Version }\end{array}$} & \multirow{2}{*}{$\mathrm{t}$} & \multirow{2}{*}{ Sig. } & \multicolumn{2}{|c|}{ Co-linear Statistics } \\
\hline & B & Std. Err. & & & & Tolerance & VIF \\
\hline (Constant) & 0.137 & 1.516 & & 0.090 & 0.929 & & \\
\hline stage of project & 0.113 & 0.379 & 0.024 & 0.298 & 0.767 & 0.699 & 1.431 \\
\hline Team size & 0.022 & 0.034 & 0.067 & 0.653 & 0.517 & 0.424 & 2.359 \\
\hline Number of evaluations & 0.008 & 0.023 & 0.026 & 0.330 & 0.743 & 0.697 & 1.436 \\
\hline Financing objectives & 0.031 & 0.008 & 1.151 & 6.252 & 0.125 & 0.133 & 7.544 \\
\hline Assigning shares & -1.747 & 0.609 & -0.117 & -1.414 & 0.163 & 0.659 & 1.516 \\
\hline $\begin{array}{l}\text { Minimum starting } \\
\text { investment amount }\end{array}$ & -0.765 & 0.399 & -0.309 & -1.918 & 0.060 & 0.173 & 5.780 \\
\hline Number of browsing & $1.274 \mathrm{E}-5$ & 0.001 & 0.021 & 0.266 & 0.791 & 0.743 & 1.346 \\
\hline Number of collectors & 0.004 & 0.025 & 0.170 & 1.955 & 0.656 & 0.592 & 1.691 \\
\hline Number of inquirers & 0.049 & 0.015 & 0.033 & 0.422 & 0.075 & 0.720 & 1.389 \\
\hline
\end{tabular}

a. Dependent variable: financing efficiency. 
of evaluations, all have a positive impact on financing efficiency, which supports Hypotheses $4 \mathrm{a}, 4 \mathrm{~b}$, and $4 \mathrm{c}$, although their impact is not significant. This indicates that some attributes of the project have a negligible effect on improving financing efficiency and accelerating financing. Generally, it can be used as a reference factor for investors when considering an investment. The numbers of people browsing, collectors, and inquiries at different stages of the project are positively related to the financing efficiency of the project, which supports Hypotheses $6 \mathrm{a}, 6 \mathrm{~b}$, and $6 \mathrm{c}$, indicating that the more concerned and interested investors are, the higher the financing efficiency. Of these factors, the number of inquiries has the most significant impact on financing efficiency.

\subsection{Herding Effect Model}

We used $t_{1}=20$ and $t_{2}=40$ to obtain the financing conditions of each project on the 20th and 40th days after the project was launched. We used the MNL market share model to analyze whether financing progress in the previous 20 days has an impact on financing over the next 20 days, and confirmed the existence of the herding effect in crowdfunding. The following regression results were obtained in Table 4.

It can be seen that at the $10 \%$ significance level, the variables "percentage of fund financed" and "number of evaluations" have a significant positive correlation with the financing market share, while the other variables do not have a significant correlation.

The variable relating to progress in financing the project, "percentage of fund financed," shows a significant positive correlation with the financing market share. This indicates that the larger the percentage of the fund financed in the early period, the faster the financing progress, and the more positive the impact on obtaining a greater financing market share in the later period. This supports Hypothesis 7. On the one hand, the higher percentage of the fund financed suggests that the project is closer to successful financing, and that investment in

Table 4. Regression results for the herding model.

\begin{tabular}{ccccc}
\hline Indep. Var. & Coeff. & Std. Err. & $\mathrm{t}$ & $\mathrm{P}>\mathrm{t}$ \\
$\begin{array}{c}\text { Percentage of fund financed } \\
\text { stage of project }\end{array}$ & $2.064^{* *}$ & 1.472 & 1.402 & 0.068 \\
Team size & 0.211 & 0.439 & 0.482 & 0.633 \\
Number of evaluations & 0.026 & 0.034 & 0.773 & 0.444 \\
Financing objectives & $0.029^{*}$ & 0.024 & 1.174 & 0.098 \\
Assigning shares & 0.032 & 0.017 & 1.931 & 0.160 \\
Minimum starting investment amount & -0.635 & 0.779 & -0.815 & 0.420 \\
_cons & -0.105 & 0.363 & -0.290 & 0.773
\end{tabular}

Note: ${ }^{\star}$ and ${ }^{\star *}$ represent significance at the $5 \%$ and $10 \%$ levels, respectively. 
projects that have a high percentage of funding financed can reduce the likelihood of failure. On the other hand, the higher percentage of the fund financed shows that the project is more popular. Therefore, investors are more likely to share the risk. In terms of the basic project attributes, the variable "number of evaluations" shows a significant positive correlation with the financing market share. A greater number of investors' evaluations of the project can also promote the project and help to obtain more financing in the later period, which confirms the herding effect to a certain extent.

\section{Conclusions}

The main conclusions are as follows. Financing objectives, the number of shares assigned, and the number of inquiries all have a significant impact on investors' willingness to invest the strength that affects the probability of successful project financing. Therefore, setting a reasonable level in terms of financing objectives, properly assigning shares, and displaying confidence in the project can all positively affect investors' willingness to invest. Meanwhile, inquirers are potential investors, and so the project sponsor should strengthen the focus on inquirers, striving to convert them into actual investors, thereby increasing the chances of successful financing of the project.

The minimum initial investment amount and the number of inquiries both have a significant impact on financing efficiency, the improvement of which can reduce the time cost and accelerate the successful financing of the project. Therefore, it is necessary to set an appropriate minimum initial investment amount to enable more ordinary investors to participate in the project. Moreover, effective conversion of inquirers into investors increases financing efficiency and accelerates the successful financing of the project.

The results show that there is a herding effect in relation to the crowdfunding process, and thus early project financing can promote greater levels of financing in the later period. Therefore, project sponsors should focus on early project financing and ensure that the project quickly gains attention and investment following its launch via the effective use of their social networks to encourage later investors and quickly achieve successful financing of the project.

\section{Acknowledgements}

This work was supported, in part, by the National Natural Science Foundation of China (Grant Nos. 70801066, 71071167, 71071168, 71371200), and by a grant from Sun Yat-sen University Basic Research Funding (Grant Nos. 1009028, 1109115, 16wkjc13).

\section{References}

[1] Mollick, E. (2014) The Dynamics of Crowdfunding: An Exploratory Study. Journal of Business Venturing, 29, 1-16. https://doi.org/10.1016/j.jbusvent.2013.06.005

[2] Bradford, C.S. (2012) The New Federal Crowdfunding Exemption: Promise Unful- 
filled. Social Science Electronic Publishing, 40, 195-249.

https://ssrn.com/abstract=2066088

[3] Klöhn, L. and Hornuf, L. (2012) Crowdinvesting in Deutschland. Zeitschrift Für Bankrecht Und Bankwirtschaft, 24, 237-266.

https://doi.org/10.15375/zbb-2012-0401

[4] Huang, J.Q. and Xin, Q.L. (2013) Crowdfunding: The Concept, Characteristics and Enlightenment of the New-Type Network Financing Model. International Finance, 9, 64-69.

[5] Tomczak, A. and Brem, A. (2013) A Conceptualized Investment Model of Crowdfunding. Venture Capital, 15, 335-359.

https://doi.org/10.1080/13691066.2013.847614

[6] Belleflamme, P., Omrani, N. and Peitz, M. (2015) The Economics of Crowdfunding Plat-Forms. Information Economics and Policy, 33, 11-28.

https://www.researchgate.net/publication/273850822

https://doi.org/10.1016/j.infoecopol.2015.08.003

[7] Belleflamme, P., Lambert, T. and Schwienbacher, A. (2014) Crowdfunding: Tapping the Right Crowd. Journal of Business Venturing, 29, 585-609.

https://doi.org/10.1016/j.jbusvent.2013.07.003

[8] Hemer, J. (2011) A Snapshot on Crowdfunding. Working Papers "Firms and Region".

[9] De Buysere, K., Gajda, O., Kleverlaan, R., Marom, D. and Klaes, M. (2012) A Framework for European Crowdfunding. European Crowdfunding Network (ECN). https://www.fundraisingschool.it/wp-content/uploads/2013/02/European-Crowdfu nding-Framework-Oct-2012.pdf

[10] Ahlers, G.K.C., Cumming, D., Günther, C. and Schweizer, D. (2015) Signaling in Equity Crowdfunding. Entrepreneurship Theory \& Practice, 39, 955-980.

https://doi.org/10.1111/etap.12157

[11] Frydrych, D., Bock, A.J., Kinder, T. and Koeck, B. (2014) Exploring Entrepreneurial Legitimacy in Reward-Based Crowdfunding. Venture Capital, 16, 247-269. https://doi.org/10.1080/13691066.2014.916512 